Supporting information for

\title{
Reactions of Dimethoxycarbene with Dimethyl 2,3-Dicycanomaleate and Fumarate.
}

\author{
Anna Sliwinska and John Warkentin* \\ Department of Chemistry, McMaster University \\ Hamilton, Ontario, L8S4M1
}

Compound 6 was obtained as primary product by thermolysis of 1.3 eq. of the DMC source in benzene in the presence of fumarate 2 or maleate 3, in a degassed, sealed tube at $50{ }^{\circ} \mathrm{C}$ for 24 hours. Nearly pure 6 was isolated from reaction mixture by washing with hexane to remove most of the $p$-methoxyacetophenone byproduct. Any attempt to prepare a pure sample of 6 led to its hydrolysis and formation of succinates 7. The yield of the crude 6 exceeded 90\%; ${ }^{1} \mathrm{H}$ NMR $\left(600 \mathrm{MHz}, \mathrm{CDCl}_{3}\right) \delta: 3.50(\mathrm{~s}, 3 \mathrm{H}), 3.68(\mathrm{~s}, 3 \mathrm{H}), 3.91(\mathrm{~s}$, $3 \mathrm{H}), 4.14(\mathrm{~s}, 3 \mathrm{H}) ;{ }^{13} \mathrm{C} \mathrm{NMR}\left(150.9 \mathrm{MHz}, \mathrm{CDCl}_{3}\right) \delta: 52.8,53.5,54.7,59.0,59.5,59.8$, 112.6, 113.4, 120.6, 162.8, 168.1; HRMS (CI, $\left.\mathrm{NH}_{3}\right) \mathrm{m} / \mathrm{z}$ : calc'd for $\mathrm{C}_{11} \mathrm{H}_{13} \mathrm{~N}_{2} \mathrm{O}_{6}(\mathrm{M}+\mathrm{H})^{+}$ 269.0774; found 269.0766. 
${ }^{1} \mathrm{H}$ NMR of 6

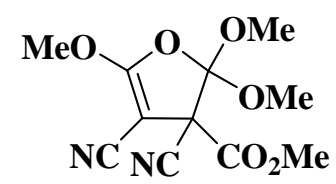

IN N

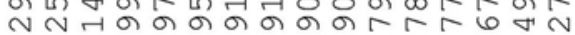

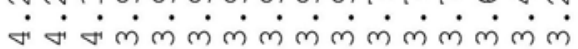

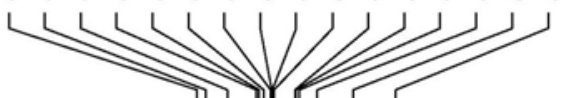

6
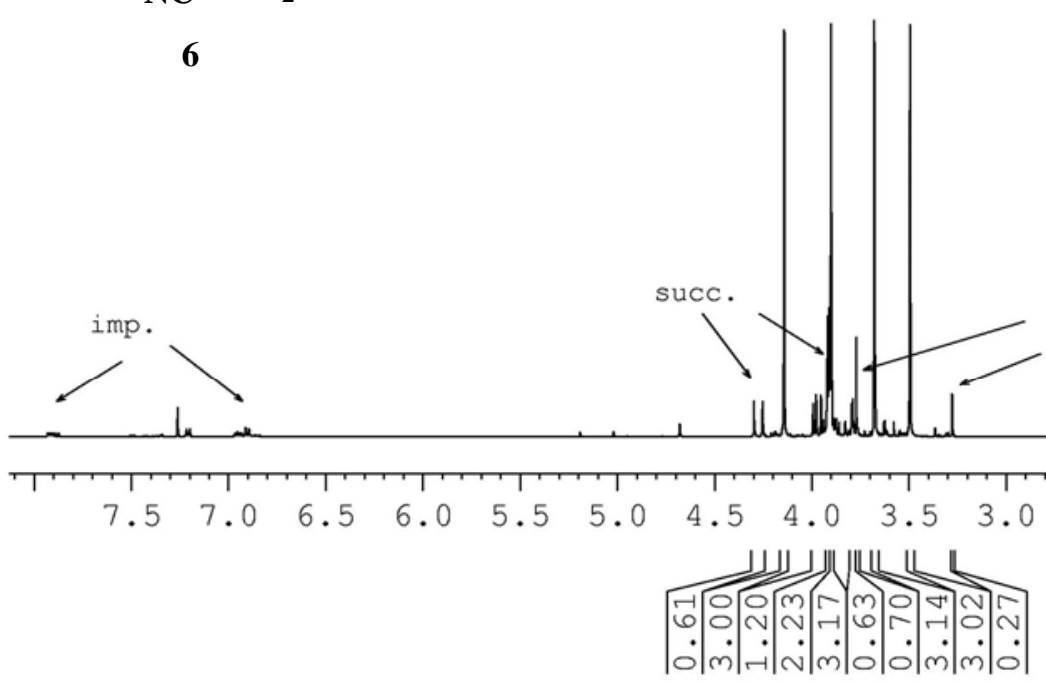

${ }^{13} \mathrm{C}$ NMR of 6
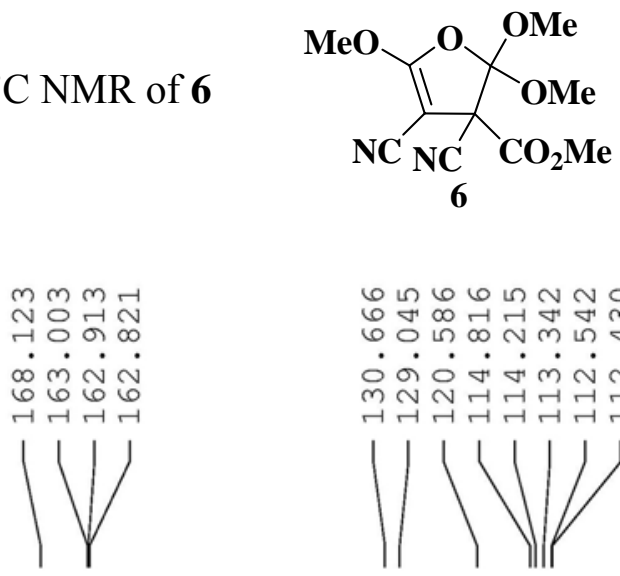

6 เ 6 เ $6 \nabla \infty$ म

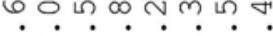
の०

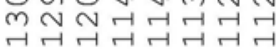

maा चन न ה

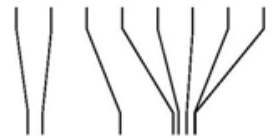
ה
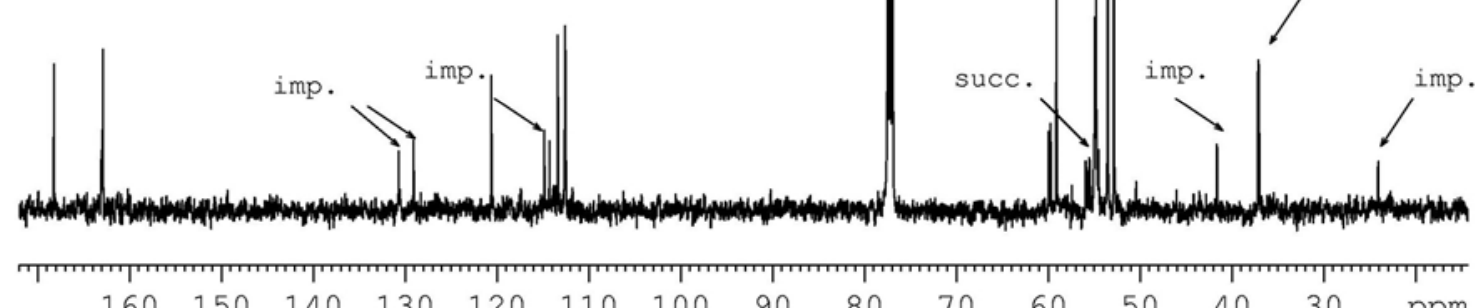
A mixture of succinates $\mathbf{7}$ was obtained through attempts to purify dihydrofurane $\mathbf{6}$ on silica gel. Dense oil, yield $80 \% ;{ }^{1} \mathrm{H}$ NMR of the mixture of isomers in ca 1:1 ratio (500 $\mathrm{MHz}, \mathrm{CDCl}_{3}$ ) $\delta: 3.921$ (s, 6H), 3.929 (s, 6H), 4.24 (s, 2H), 4.29 (s, 2H), ${ }^{13} \mathrm{C}$ NMR (125.8 $\mathrm{MHz}, \mathrm{CDCl}_{3}$ ) $\delta: 37.02,37.11,54.87,54.94,112.45,112.62,162.92,163.03$; HRMS (CI, $\left.\mathrm{NH}_{3}\right)$ m/z: calc'd for $\mathrm{C}_{8} \mathrm{H}_{9} \mathrm{~N}_{2} \mathrm{O}_{4}(\mathrm{M}+\mathrm{H})^{+}$197.0562; found 197.0563.

${ }^{1} \mathrm{H}$ NMR of 7
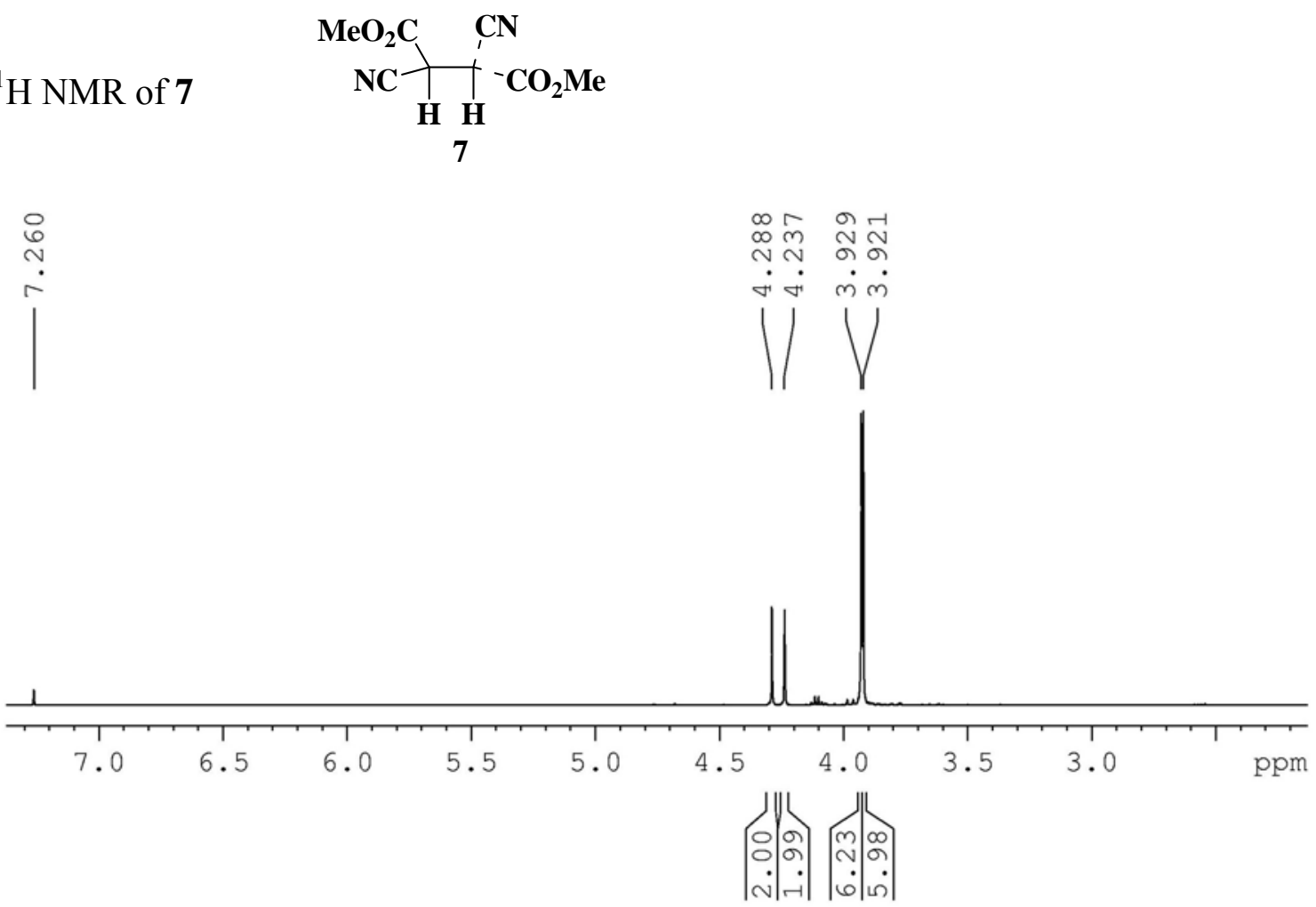


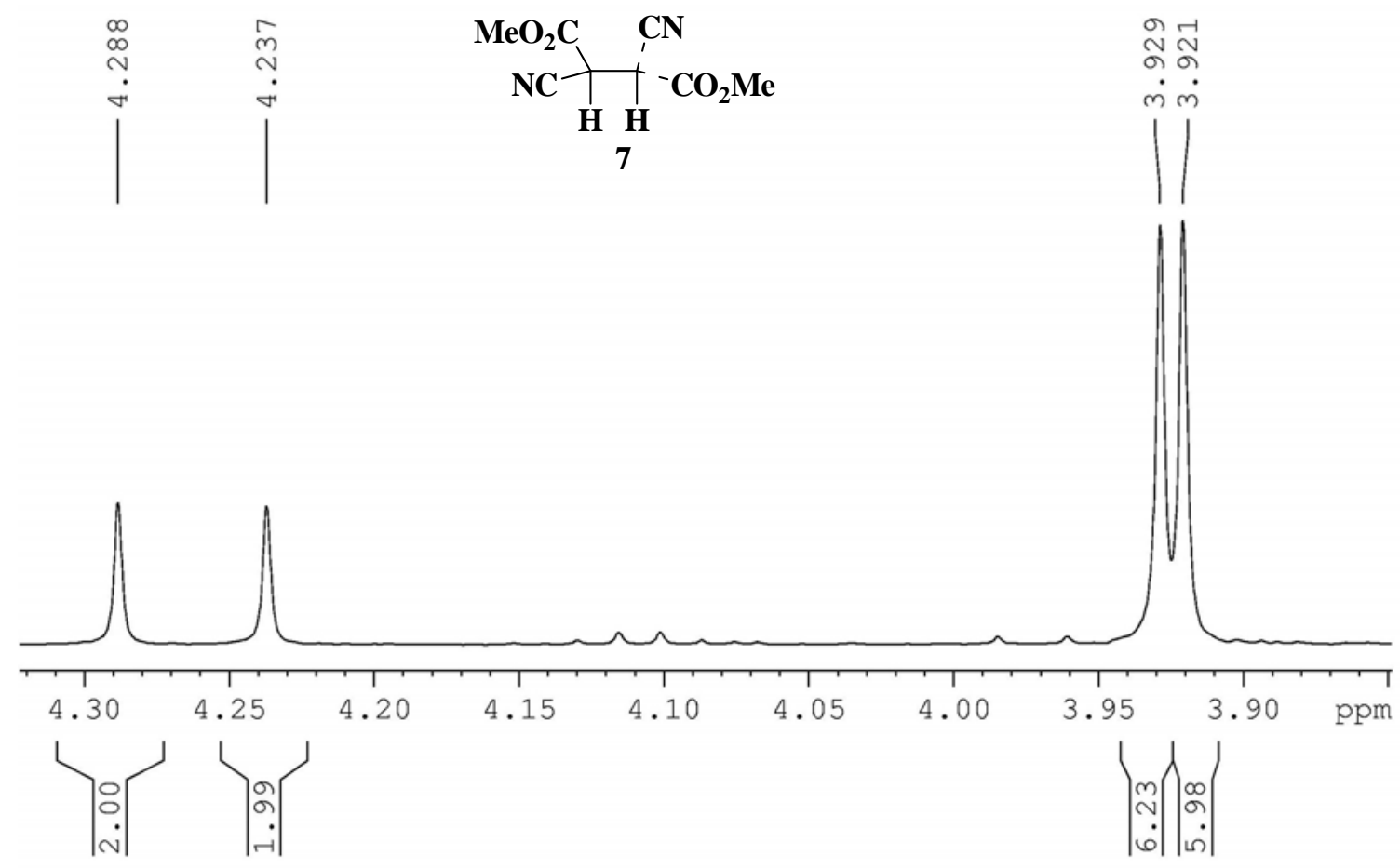

${ }^{13} \mathrm{C}$ NMR of 7
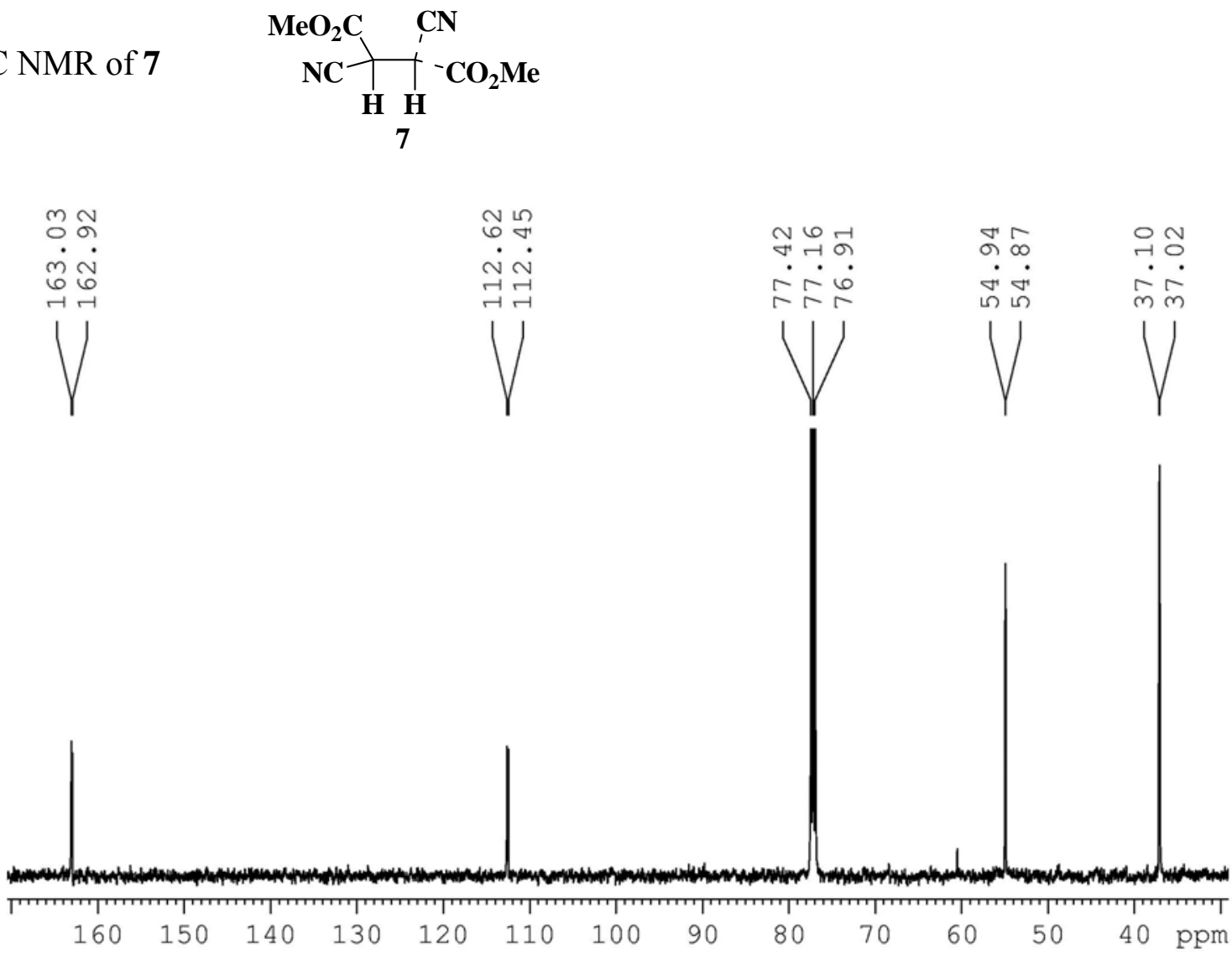

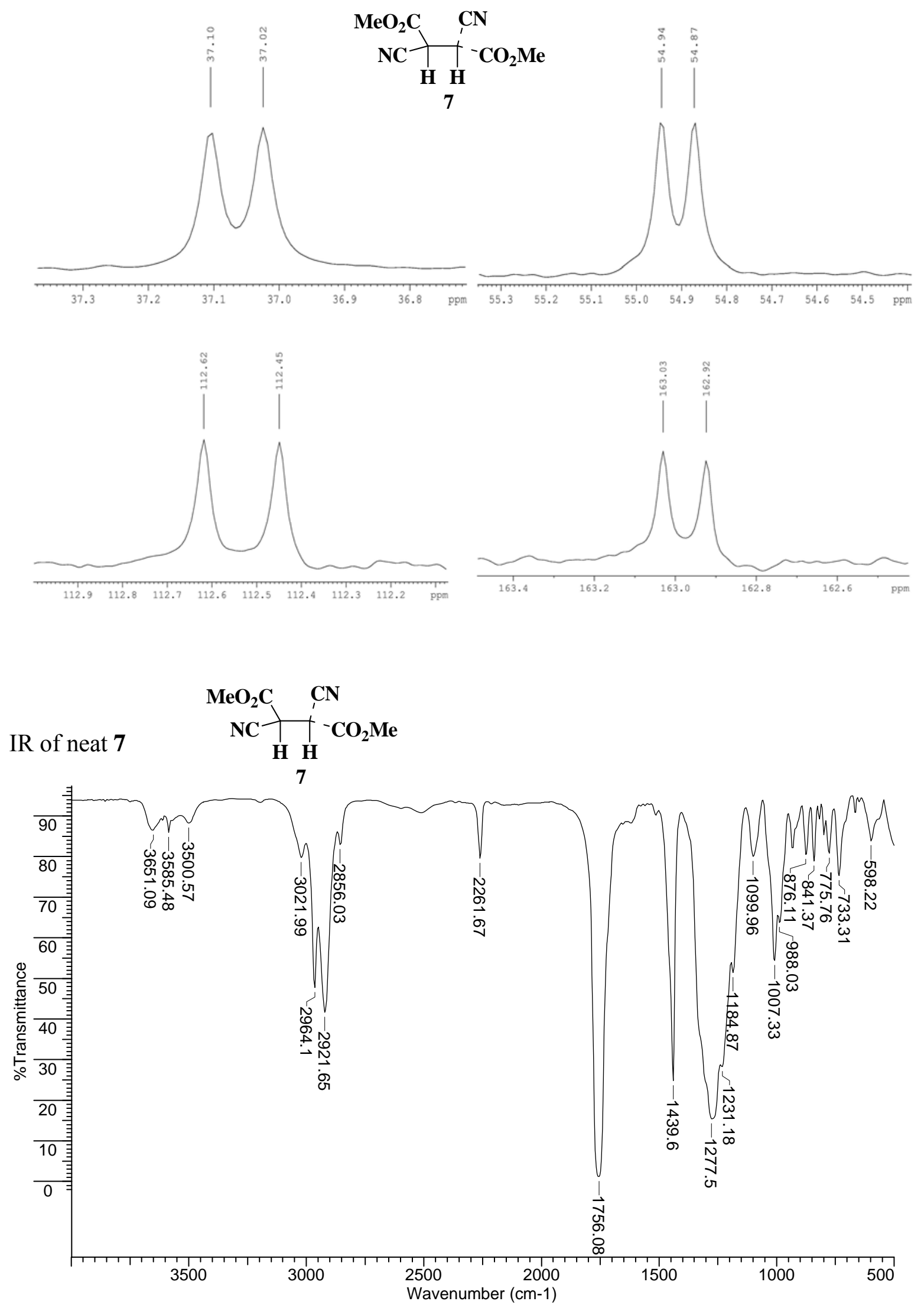